\title{
Convergent Validity and Minimal Clinically Important Difference of the Maugeri Foundation Respiratory Failure Questionnaire (MRF-28) and the Chronic Obstructive Pulmonary Disease-Specific Health-Related Quality of Life questionnaire (VQII)
}

This article was published in the following Dove Press journal: International Journal of Chronic Obstructive Pulmonary Disease

\author{
Jérémy B Coquart $\mathbb{D}^{\prime}$ \\ Natacha Heutte (D) \\ Gaelle Terce ${ }^{2}$ \\ Jean-Marie Grosbois ${ }^{3}$ \\ 'Université de Rouen-Normandie, UFR \\ STAPS, CETAPS, EA 3832, Mont Saint \\ Aignan F-7682I, France; ${ }^{2}$ Centre \\ Hospitalier de Béthune, Service de \\ Pneumologie et de Réhabilitation \\ Respiratoire, Beuvry F-62660, France; \\ ${ }^{3}$ FormAction Santé, Pérenchies F-59840, \\ France
}

Purpose: Short and easy questionnaires have been developed to assess the health-related quality of life (HRQoL) in patients with chronic obstructive pulmonary disease (COPD), such as the Maugeri Foundation Respiratory Failure Questionnaire (MRF-28) and the COPD-specific HRQoL Questionnaire (VQ11). Both are valid, reliable, and sensitive, but their minimal clinically important differences (MCID) are unknown. Consequently, this study aimed to confirm the convergent validities of the MRF-28 and VQ11 and establish their MCID. A retrospective design was used to evaluate the effect of individual home-based pulmonary rehabilitation (PR) in 400 COPD patients.

Patients and methods: Exercise tolerance, anxiety and depression based on the Hospital Anxiety and Depression Scale (HADS), and HRQoL using three questionnaires (MRF-28, VQ11, and the Visual Simplified Respiratory Questionnaire: VSRQ) were assessed before and after an individualized home-based PR program (5 sessions of 30-45 mins/week for 8 weeks including a weekly session supervised by a team member).

Results: PR improved all measured variables $(p<0.0001)$. The correlations were significant $(p<0.0001)$ between VSRQ and MRF-28 $(r=-0.685$ at baseline and $\mathrm{r}=-0.686$ after the PR program), and between VSRQ and VQ11 ( $\mathrm{r}=-0.691$ at baseline and $\mathrm{r}=-0.753$ after the PR program). Moreover, changes in score (delta between after and before PR program) of VSRQ were also significantly correlated $(p<0.0001)$ to changes in score of MRF-28 $(\mathrm{r}=-0.372)$ and VQ11 $(\mathrm{r}=-0.423)$. Last, we calculated MCID of -5.2 and -2.0 units for MRF-28 and VQ11, respectively.

Conclusion: The MRF-28 and VQ11 can be used in routine practice to evaluate the effects of PR on the HRQoL of COPD patients, with MCID of -5.2 and -2.0 , respectively.

Keywords: visual simplified respiratory questionnaire, VSRQ, home-based pulmonary rehabilitation

\section{Introduction}

Correspondence: Jérémy B Coquart Université de Rouen-Normandie, UFR STAPS, CETAPS, EA 3832, Mont Saint Aignan F-7682I, France Tel +33235 I46 775

Email jeremy.coquart@univ-rouen.fr
Chronic obstructive pulmonary disease (COPD) is associated with progressive dyspnea and reduced exercise tolerance, both of which encourage sedentary lifestyles and cause considerable deterioration of health-related quality of life (HRQoL). ${ }^{1}$ Symptom relief and improved HRQoL should be major goals of COPD treatment. ${ }^{2-4}$ Among the non-drug 
treatments, pulmonary rehabilitation (PR), a comprehensive personalized intervention including physical activities, health education and psychological support, has been shown to be beneficial, regardless of age, sex, severity of airflow limitation or place where it is performed (hospital, outpatient clinic, or home). ${ }^{2}$ Indeed, recent studies have confirmed that homebased PR is safe and effective and improves HRQoL in these patients. $^{2,4-7}$

Although generic questionnaires can be used to assess HRQoL in COPD patients, disease-specific tools may be more appropriate to obtain better responsiveness. ${ }^{8,9}$ Among respiratory disease-specific HRQoL questionnaires, the $\mathrm{St}$ George's respiratory questionnaire (SGRQ) ${ }^{10}$ and the chronic respiratory questionnaire $(\mathrm{CRQ})^{11}$ are frequently used for COPD patients. ${ }^{4}$ However, the length of the SGRQ (more than 50 items generally requiring $20 \mathrm{mins})^{8}$ limits its routine use, and the individualization of the dyspnea domain of the CRQ likely increases its complexity for both patients and interviewers. ${ }^{12}$ Therefore, a COPD-specific questionnaire was developed for quick and easy (ie, approximately 3-4 mins) ${ }^{13}$ assessment of HRQoL in outpatient settings, real-life studies, and/or routine individual care: the visual simplified respiratory questionnaire (VSRQ). ${ }^{3}$ The validity (comparison to SGRQ), reliability, and responsiveness of the VSRQ in COPD patients have already been demonstrated. ${ }^{3,14}$ Nevertheless, in the past few years, two other respiratory disease-specific questionnaires have been increasingly used in PR centres: the Maugeri Foundation respiratory failure questionnaire $(\mathrm{MRF}-28)^{5,15-20}$ and the COPD-specific HRQoL questionnaire (VQ11). ${ }^{5,13,19,21}$ The interest in both, compared to the VSRQ, is that they provide a global score of HRQoL but also and most importantly, they evaluate special dimensions of HRQoL.

The MRF-28 is composed of 28 items covering three theoretical components (daily activity, cognitive function, and invalidity). ${ }^{15}$ Its validity and reliability were confirmed in 81 patients treated with home mechanical ventilation for chronic respiratory failure but only 12 of the patients had COPD. ${ }^{15}$ The validity therefore needs to be confirmed in a larger sample of COPD patients. Moreover, to our knowledge, the minimal clinically important difference (MCID) of the MRF-28 is unknown. The VQ11 comprises 11 items distributed across three components (functional: 3 items, psychological: 4 items, social: 4 items) and a top level combining them. ${ }^{13}$ The VQ11 is valid and reliable, ${ }^{13,21}$ but its responsiveness for homebased PR needs to be determined, as does its MCID. ${ }^{13}$
In this study, we therefore assessed the validity, responsiveness, and MCID of the MRF-28 and the VQ11 in a retrospective study designed to evaluate the effect of individual home-based PR on HRQoL in COPD patients. The VSRQ, which is valid, reliable, sensitive, ${ }^{3}$ and specifically developed for COPD patients, was taken as the reference. We hypothesized that home-based PR would be feasible and effective in improving HRQoL in COPD patients, and that the MRF-28 and VQ11 would be useful tools to evaluate these benefits.

\section{Materials and Methods Study Design}

This 6-year monocentric observational study, which included consecutive COPD patients managed by outpatient $\mathrm{PR}$, respects the "strengthening the reporting of observational studies in epidemiology" (STROBE) statement. ${ }^{22}$ All data were collected prospectively and were entered into our rehabilitation computerized medical records (according to the routine/standard management of patient). Retrospective analysis was executed from data collected between 2012 and 2017. All patients were following a home-based PR program.

Briefly and as described elsewhere, this individualized home-based PR program consisted of a 90 min session once a week for 8 weeks, based on an educational needs assessment. $^{5,19}$ It comprised endurance exercise, the resumption of the physical activities of daily living, therapeutic education, psychosocial support, and motivational communication to encourage health behavior changes and self-management. This weekly session was conducted under the direct supervision of a team member. Patients were expected to continue performing the endurance exercises on their own the other days of the week, according to a personalized action plan.

Initially, individual endurance exercise on a cycle ergometer was performed in sequences of 10 mins or less. They were asked to exercise at least 5 days per week, with the goal being to reach 30 to 45 mins per day, in one or several sessions. ${ }^{5,19,23}$ The exercise intensity was prescribed on the basis of dyspnea symptoms (generally 3-4 on Borg's category scale with ratio properties) or effort perception (generally 11-13 on Borg's rating of perceived exertion scale). The patients were encouraged to increase the time spent in daily living activities. In addition, three muscle strengthening exercises for the upper and lower limbs were systematically proposed, lasting 10-15 mins 
per day and using weights and dumbbells and/or elastic bands. Each exercise comprised 10 repeated movements. A $1 \mathrm{~min}$ recovery period was observed between exercises. Warm-up and stretching exercises were also recommended together with balance exercises whenever necessary.

The PR agreement given to the patients before PR included an accident protocol. An accident was defined as death, hospitalization or emergency care required for heart or orthopedic incidents during the 8 weeks of PR. The patient and/or the physical therapist could declare the accident. Patients were asked to interrupt all physical activities in the case of any abnormal sensations, especially chest or joint pain, and to contact both the rehabilitation team and the attending physician.

\section{Participants}

In this observational study, 485 patients with COPD who were following home-based PR were consecutively included. COPD diagnosis was confirmed according to international guidelines. ${ }^{24}$ COPD patients were excluded if they had dementia or poorly controlled psychiatric illness, neurological sequelae, or bone and joint diseases preventing physical activity.

\section{Assessments}

Patients were evaluated at home just before (ie, $\mathrm{T}_{0}$ ) and after PR (ie, $\mathrm{T}_{2}$ ). During a medical consultation at baseline, sociodemographic (ie, age, sex, body mass, height, body mass index and socioeconomic deprivation score) and spirometric data (ie, forced expiratory volume in one second: $\mathrm{FEV}_{1}$, forced vital capacity: $\mathrm{FVC}, \mathrm{FEV}_{1} / \mathrm{FVC}$ and the severity of airflow limitation), as well as treatment (ie, long-term oxygen therapy: LTOT, non-invasive ventilation: NIV, continuous positive airways pressure: CPAP) were collected. As described elsewhere, ${ }^{5,19}$ the evaluation of exercise tolerance included a 10 times sit-to-stand test (10STS), a timed up-and-go test (TUG), and a 6 min stepper test (6MST). The 10STS consists of standing up until reaching full knee extension and sitting back down 10 times as fast as possible while seated at the front of a 42-cm-high chair. ${ }^{25}$ During the TUG, patients stand up from a standard armchair, walk $3 \mathrm{~m}$, turn, walk back, and sit down again as quickly as possible. ${ }^{26}$ Last, the number of steps taken in 6 mins was collected during a $6 \mathrm{MST}$ as previously described. $^{27}$ The stepper (Go Sport ${ }^{\circledR}$, Grenoble, France), with a step height fixed at $20 \mathrm{~cm}$, was placed near a wall to support patients if they became unbalanced or exhausted.
The patients could freely regulate their stepping rate to reach the highest number of strokes.

Psychological status was assessed by the hospital anxiety and depression (HAD) scale, $^{28}$ and HRQoL was assessed by the MRF-28, ${ }^{15}$ VQ $11,{ }^{21}$ and VSRQ. ${ }^{3}$ The HAD scale determined the patient's psychological state in terms of anxiety and depression. ${ }^{28}$ This questionnaire has 14 items ( 7 items for each psychological state), with responses scored on a scale of 0-3 to indicate symptom frequency (the higher the frequency, the higher the score is). The MRF-28 is composed of 28 items covering three theoretical components (daily activity, cognitive function, and invalidity) and gives a final score ranging from 0 to 100, with higher scores reflecting a higher degree of impairment. ${ }^{15}$ The VQ11 comprises 11 items distributed across three components (functional: 3 items, psychological: 4 items, social: 4 items) and a top level combining these three components. ${ }^{21}$ Higher scores indicate less favorable quality of life. Last, the VSRQ is a valid, reliable, and sensitive questionnaire to assess HRQoL, specially developed for patients with COPD. ${ }^{3}$ It comprises eight visual analog scales ranging from 0 to 10 , with a total score ranging from 0 to 80 . Higher scores indicate better HRQoL. The MCID of the VSRQ is known: +3.4 units. $^{3}$ Consequently, the VSRQ was taken as a reference for comparison with the MRF-28 and VQ11.

\section{Ethical Approval}

All procedures performed in this study were in accordance with the Helsinki declaration and its amendments. Moreover, the research protocol was approved by the Observational Research Protocol Evaluation Committee of the Frenchlanguage Society of Pulmonology (CEPRO 2017-007), and written informed consent was obtained from each participant.

\section{Statistical Analysis}

Descriptive statistics included the number of cases and percentages for categorical variables, and median, range or means and standard deviations (SD) for continuous variables. Normal Gaussian distribution of the data was verified by the Shapiro-Wilk test. At the baseline $\left(\mathrm{T}_{0}\right)$, the participant characteristics included in the statistical analysis were compared to those of nonparticipants (ie, patients excluded because of refusal to participate or lost to follow-up) from Student's $t$-tests or Mann-Whitney $U$-tests for continuous data. For categorical data, the frequencies were compared using Pearson's Chi-squared test or Fisher's exact test when 
appropriate. To test the effect of PR, paired Student's $t$-tests or Wilcoxon matched pairs tests were used.

Spearman correlation coefficients were calculated to examine the convergent validity between the VSRQ (ie, the anchor) and the other questionnaires (ie, MRF-28 and VQ11). These correlation coefficients were classed as "very high" ( $r \geq 0.90)$, "high" $(0.70 \geq r \leq 0.89)$, "moderate" $(0.50 \geq r \leq 0.69)$, or "low" $(0.26 \geq r \leq 0.49)$. ${ }^{29}$

As triangulation is recommended to measure MCID, ${ }^{30}$ both anchor-based (using the VSRQ as the anchor) and distribution-based (half a standard deviation and a small Cohen's effect size) methods were used to calculate the MCID for MRF-28 and VQ11. According to Cohen, ${ }^{31}$ the magnitude of the difference can be considered to be trivial ( $\mathrm{ES}<0.2)$, small $(0.2 \geq \mathrm{ES}<0.5)$, moderate $(0.5 \geq \mathrm{ES}<0.8)$, or large ( $E S \geq 0.8$ ). A receiver operating characteristic (ROC) curve approach was used, with dichotomized VSRQ responses (less than 3.4 units vs 3.4 units or more, as proposed by Perez et $\mathrm{al}^{3}$ ) as dependent variables, and the change score for each questionnaire as independent. ${ }^{32}$ An optimal cut-off value for each questionnaire - ie, the one that maximized Youden's index (maximizes both sensitivity and specificity) - was identified.

\section{Results}

\section{Description of Sample}

A total of 485 patients were solicited to participate in the study, and 7 of them refused (Figure 1). The sociodemographic and medical characteristics at inclusion are summarized in Table 1. Differences between participants $(n=400)$ and nonparticipants $(\mathrm{n}=78)$ are presented in Table 2. Mainly, the nonparticipants were excluded because of physical incapacity $(n=21)$, hospitalization ( $n=16$ ), stopping the home-based PR without explanation ( $n=13)$, or loss of motivation to continue the program $(\mathrm{n}=10$, Figure 1). The nonparticipants were significantly older $(68.3 \pm 10.9$ vs $63.5 \pm 11.1$ years $)$ and had lower $\mathrm{FEV}_{1}(34.3 \pm$ 13.5 vs $40.1 \pm 17.8 \%)$ and FVC $(56.0 \pm 18.7$ vs $65.2 \pm 20.0 \%)$ compared to participants $(p \leq 0.01$, Table 2$)$.

\section{Effects of Home-Based PR}

The effects of the home-based PR on exercise tolerance (ie, 10STS, TUG, and 6MST) psychological status (ie, anxiety and depression from the HAD questionnaire), and HRQoL (ie, from each dimension of the MRF-28, VQ11 and VSRQ) are summarized in Table 3. All measures were significantly improved after the program $(p<$ 0.0001 , Table 3), except for the dimension of cognitive function on the MRF-28 (for which only a trivial effect was noted); all other measures showed small (but significant) or moderate effects (Table 3).

\section{Convergent Validity of HRQoL Questionnaires}

The associations between the anchor (ie, VSRQ) and HRQoL (ie, MRF-28 and VQ11) at $\mathrm{T}_{0}$ and $\mathrm{T}_{2}$ and the delta (ie, $\left.\mathrm{T}_{2}-\mathrm{T}_{0}\right)$ were all significant $(p<0.0001$, Table 4$)$. The correlation coefficients ranged from $r=-0.372$ to -0.686 for MRF-28, and $r=-0.423$ to -0.753 for VQ11 (Table 4).
Time from the start of home-based PR program (T0):

Time from the end of home-based PR program (T2):

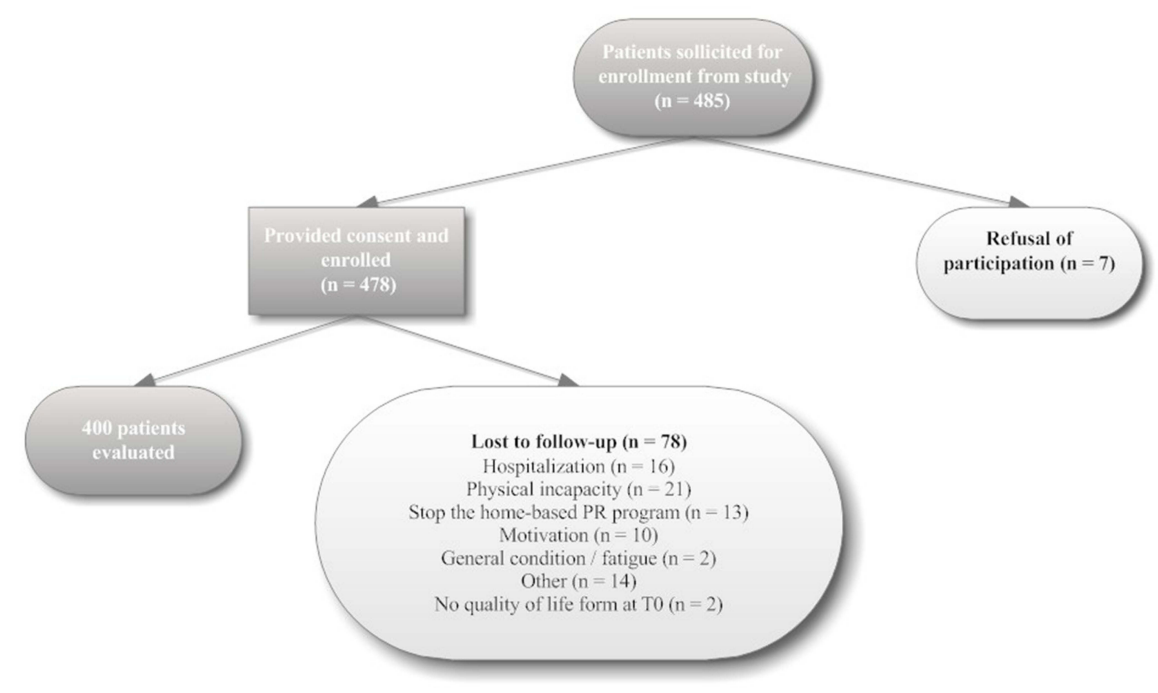

Figure I Flow diagram of patients with chronic obstructive pulmonary disease managed by home-based pulmonary rehabilitation program. 
Table I Characteristics of Patients Solicited to Participate in the Study

\begin{tabular}{|c|c|}
\hline & $\begin{array}{l}\text { n (\%) or Median } \\
\text { (Range) }\end{array}$ \\
\hline Sample size & $485(100)$ \\
\hline Age (y) & $64.0(22.0-89.0)$ \\
\hline Men (\%) & $159(32.8)$ \\
\hline Body mass $(\mathrm{kg})$ & $74.0(35.0-150.0)$ \\
\hline Height (m) & $1.69(1.40-1.90)$ \\
\hline Body mass index $\left(\mathrm{kg} / \mathrm{m}^{2}\right)$ & $26.1(14.0-56.2)$ \\
\hline $\mathrm{FEV}_{\mathrm{I}}(\mathrm{L})$ & $0.93(0.37-4.88)$ \\
\hline $\mathrm{FEV}_{\text {, }}$ (\% theoretical value) & $36.0(13.0-101.0)$ \\
\hline FVC (L) & $2.1(0.6-5.1)$ \\
\hline FVC (\% theoretical value) & $62.0(18.0-118.0)$ \\
\hline $\mathrm{FEV}_{\mathrm{I}} / \mathrm{FVC}$ & $49.0(24.0-70.0)$ \\
\hline Mild airflow limitation (FEV $1 \geq 80 \%$ ) & $5(1.0)$ \\
\hline Moderate airflow limitation $(50 \% \leq \mathrm{FEV},<80 \%)$ & $79(16.3)$ \\
\hline Severe airflow limitation $(30 \% \leq \mathrm{FEV},<50 \%)$ & $161(33.2)$ \\
\hline Very severe airflow limitation ( $\mathrm{FEV},<30 \%)$ & $129(26.6)$ \\
\hline Refusal & $\mathrm{I}(0.2)$ \\
\hline Missing & $110(22.7)$ \\
\hline LTOT & I7I (35.3) \\
\hline LTOT + NIV & $137(28.3)$ \\
\hline LTOT + CPAP & $14(2.9)$ \\
\hline NIV & $24(5.0)$ \\
\hline CPAP & $27(5.6)$ \\
\hline No medical equipment & $112(23.0)$ \\
\hline Socioeconomic deprivation score & $37.0(7.0-92.0)$ \\
\hline
\end{tabular}

Abbreviations: CPAP, continuous positive airways pressure; $\mathrm{FEV}_{\mathrm{l}}$, forced expiratory volume in one second; FVC, forced vital capacity; LTOT, long-term oxygen therapy; NIV, non-invasive ventilation.

\section{Determination of MCID}

As the lower limit of the area under the ROC curve was sometimes $<0.5$ ( 0.481 for MRF-28 and 0.436 for VQ11), the relationship between the change score and the anchor was considered insufficient to estimate the MCID from this statistical analysis (ie, ROC curve). Therefore, distribution-based (half a standard deviation and a small Cohen's effect size) methods were used to determine it (Table 5). For each variable, the mean was calculated from these two methods. The MCID were -5.2 units for MRF$28,-2.0$ units for VQ11, and +3.4 units for VSRQ.

\section{Discussion}

This study shows that $16.1 \%$ of the patients did not complete the home-based PR. The two main reasons, physical incapacity (26.9\%) and hospitalization (20.5\%, Figure 1) explained $47.4 \%$ of PR abandonment. At baseline, these nonparticipants were significantly older and had lower $\mathrm{FEV}_{1}$ than the participants (Table 2). These results are unsurprising since body mass index (non-significantly decreased in the current study, $p=0.184$, Table 2), age, and $\mathrm{FEV}_{1}$ are predictors of hospitalization and death in COPD patients. ${ }^{33}$ Moreover, $\mathrm{FEV}_{1}$ is known to be significantly associated with COPD exacerbations. ${ }^{34}$ To summarize, the nonparticipants did not complete the PR because they were older and had greater airflow limitation, which is known to lead to physical incapacity, exacerbations, and thus hospitalizations and death in COPD patients.

In line with the literature, ${ }^{5,19,35}$ this study confirms that a personalized and comprehensive home-based PR (with one visit per week for 8 weeks) including physical training, health education, psychological support, and motivational communication is feasible and effective in COPD patients and can significantly improve exercise tolerance, anxiety and depression, and HRQoL (Table 3). As previously indicated, ${ }^{5}$ home-based PR is therefore an alternative to outpatient or inpatient rehabilitation and may make it easier for a greater number of patients worldwide to benefit from PR.

The VSRQ is used to measure HRQoL in patients with pulmonary disease, ${ }^{14,36}$ especially when PR is executed at home. ${ }^{5,16,19,23,35}$ It is a valid, reliable, and sensitive questionnaire, ${ }^{3,14}$ and thus it was our reference (ie, the anchor) to confirm the convergent validity of the MRF28 and VQ11. The results showed a significant improvement in VSRQ, MRF-28, and VQ11 after PR (Table 3). Moreover, significant correlations (Table 5) were found between the VSRQ and the other HRQoL questionnaires at $\mathrm{T}_{0}(\mathrm{r}=-0.685$ and -0.691 for MRF-28 and VQ11, respectively) and $T_{2}(r=-0.686$ and -0.753 for MRF-28 and VQ11, respectively). Significant correlations were also noted for the delta $\left(T_{2}-T_{0}\right)$ between VSRQ and the other HRQoL questionnaires (Table 5). According to the literature, ${ }^{13,15,21}$ these results together confirm the convergent validity of the MRF-28 and VQ11. The validity of the MRF-28 has already been reported, with a significant correlation with the SGRQ $(r=0.78)$ in patients treated for chronic respiratory failure by home mechanical ventilation. ${ }^{15}$ The convergent validity $(p<0.05, \mathrm{r}=0.71)$ between the VQ11 and SGRQ was also reported in COPD patients. ${ }^{21}$ Therefore, the MRF-28 and VQ11 have good measurement properties and are useful tools to measure COPD-specific HRQoL in routine practice. ${ }^{21}$

The present study suggests that MRF-28 and VQ11 could be used alone or as an adjunct to VSRQ to assess the global HRQoL. However, as VSRQ includes no subscale (and provides only global score of HRQoL), MRF-28 and VQ11 could 
Table 2 Differences Between Participants and Nonparticipants

\begin{tabular}{|c|c|c|c|c|}
\hline & $\begin{array}{l}\text { Non-Participant Patients } \\
(\mathrm{n}=85)\end{array}$ & $\begin{array}{l}\text { Participant Patients } \\
(n=400)\end{array}$ & $\begin{array}{l}\text { All Patients } \\
(\mathrm{n}=485)\end{array}$ & $p$ Value \\
\hline Age $(y)$ & $68.3(10.9)$ & $63.5(11.1)$ & $64.3(11.2)$ & 0.0003 \\
\hline Men $(\%)$ & $56(65.9)$ & $270(67.5)$ & $159(32.8)$ & 0.7729 \\
\hline Body mass $(\mathrm{kg})$ & $72.8(22.0)$ & $77.8(22.3)$ & $76.9(22.3)$ & 0.0638 \\
\hline Height (m) & $1.67(8.7)$ & $1.69(8.6)$ & $1.68(8.6)$ & 0.0510 \\
\hline Body mass index $\left(\mathrm{kg} / \mathrm{m}^{2}\right)$ & $26.1(7.5)$ & $27.3(7.6)$ & $27.1(7.6)$ & 0.1843 \\
\hline $\mathrm{FEV}_{\mathrm{I}}(\mathrm{L})$ & $0.87(0.40)$ & $1.12(0.57)$ & $1.08(0.56)$ & 0.0002 \\
\hline FEV (\% theoretical value) & $34.3(13.5)$ & $40.1(17.8)$ & $39.2(17.4)$ & 0.0053 \\
\hline $\mathrm{FVC}(\mathrm{L})$ & $1.9(0.9)$ & $2.2(0.9)$ & $2.2(0.9)$ & 0.0300 \\
\hline FVC (\% theoretical value) & $56.0(18.7)$ & $65.2(20.0)$ & $63.9(20.0)$ & 0.0120 \\
\hline $\mathrm{FEV}_{\mathrm{l}} / \mathrm{FVC}$ & $45.7(11.3)$ & $49.5(12.8)$ & $49.0(12.7)$ & 0.1039 \\
\hline Mild airflow limitation ( $F E V_{1} \geq 80 \%$ ) & $0(0.00)$ & $5(1.3)$ & $5(1.0)$ & $<0.0001$ \\
\hline Moderate airflow limitation $(50 \% \leq \mathrm{FEV},<80 \%)$ & $8(9.4)$ & $71(17.8)$ & $79(16.3)$ & \\
\hline Severe airflow limitation $\left(30 \% \leq \mathrm{FEV}_{1}<50 \%\right)$ & $22(25.9)$ & $139(34.8)$ & $161(33.2)$ & \\
\hline Very severe airflow limitation $\left(\mathrm{FEV}_{1}<30 \%\right)$ & $26(30.6)$ & $103(25.8)$ & $129(26.6)$ & \\
\hline Refusal & $\mathrm{I}(\mathrm{I} .8)$ & $0(0.0)$ & $\mathrm{I}(0.2)$ & \\
\hline Missing & $28(33.0)$ & $82(20.5)$ & $110(22.7)$ & \\
\hline LTOT & $39(45.9)$ & $132(33.0)$ & $|7|(35.3)$ & 0.0570 \\
\hline LTOT + NIV & $25(29.4)$ & II $2(28.0)$ & $137(28.3)$ & \\
\hline LTOT + CPAP & $4(4.7)$ & $10(2.5)$ & $14(2.9)$ & \\
\hline NIV & $3(3.5)$ & $21(5.3)$ & $24(5.0)$ & \\
\hline CPAP & $3(3.5)$ & $24(6.0)$ & $27(5.6)$ & \\
\hline No medical equipment & II (12.9) & $101(25.3)$ & $112(23.0)$ & \\
\hline Socioeconomic deprivation score & $38.4(16.9)$ & $37.7(18.0)$ & $37.8(17.8)$ & 0.7636 \\
\hline
\end{tabular}

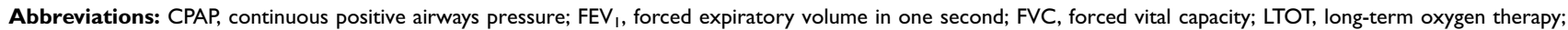
NIV, non-invasive ventilation.

be preferred. Indeed, the MRF-28 covers 3 subcomponents of $\quad$ functional, psychological, and social). ${ }^{21}$ Previously, Mahler ${ }^{37}$ HRQoL (ie, daily activity, cognitive function and invalidity) ${ }^{15}$ indicated that HRQoL refers to 3 components of health: phyand the VQ11 also provides scores from 3 subcomponents (ie, sical (eg, physical capacity), psychological (eg, self-esteem,

Table 3 Effect of the Pulmonary Rehabilitation Program

\begin{tabular}{|c|c|c|c|c|c|}
\hline & $\mathbf{T}_{\mathbf{0}}$ & $\mathbf{T}_{\mathbf{2}}$ & Mean Change & Cohen's d & $p$ Value \\
\hline IOSTS (s) & $32.4(15.8)$ & $27.6(12.3)$ & $-4.7(12.3)$ & -0.30 & $<0.0001$ \\
\hline TUG (s) & $10.8(6.7)$ & $9.5(6.8)$ & $-1.3(3.9)$ & -0.20 & $<0.0001$ \\
\hline 6MST (strokes) & 322 (159) & $390(171)$ & $+64(100)$ & 0.43 & $<0.0001$ \\
\hline HAD: anxiety state $(/ 2 \mathrm{I})$ & $9.8(4.5)$ & $8.5(4.2)$ & $-1.4(3.5)$ & -0.31 & $<0.0001$ \\
\hline HAD: depression state $(/ 2 I)$ & $8.1(4.1)$ & $6.2(4.1)$ & $-1.8(3.7)$ & -0.44 & $<0.0001$ \\
\hline HAD: global score $(/ 42)$ & $17.9(7.4)$ & $14.7(7.2)$ & $-3.2(6.2)$ & -0.43 & $<0.0001$ \\
\hline MRF-28: daily activity $(/ / 00)$ & $52.2(28.5)$ & $43.1(28.0)$ & $-9.2(21.6)$ & -0.32 & $<0.0001$ \\
\hline MRF-28: cognitive function $(/ 100)$ & $31.6(36.4)$ & $25.5(33.4)$ & $-6.1(30.0)$ & -0.17 & $<0.0001$ \\
\hline MRF-28: invalidity $(/ 100)$ & $62.4(32.3)$ & $51.9(34.2)$ & $-10.4(30.8)$ & -0.32 & $<0.0001$ \\
\hline MRF-28: global score $(/ / 00)$ & $51.2(23.1)$ & $42.5(22.9)$ & $-8.8(16.5)$ & -0.38 & $<0.0001$ \\
\hline VQII: functional (/I5) & $10.7(2.9)$ & $9.5(3.1)$ & $-1.2(2.5)$ & -0.44 & $<0.0001$ \\
\hline VQII: psychological (/20) & II.8 (3.2) & $10.6(3.4)$ & $-1.2(3.0)$ & -0.39 & $<0.0001$ \\
\hline VQII: social (/20) & $11.0(3.8)$ & $9.8(4.0)$ & $-1.1(3.3)$ & -0.30 & $<0.0001$ \\
\hline VQII: global score (/55) & $33.5(8.9)$ & $29.8(9.7)$ & $-3.5(7.5)$ & -0.42 & $<0.0001$ \\
\hline VSRQ (/80) & $31.1(15.3)$ & $39.3(16.4)$ & $+8.2(13.5)$ & 0.54 & $<0.0001$ \\
\hline
\end{tabular}

Abbreviations: HAD, hospital anxiety and depression questionnaire; MRF-28, Maugeri Foundation respiratory failure questionnaire; TUG, timed up-and-go test; VQII, COPD specific HRQoL questionnaire; VSRQ, visual simplified respiratory questionnaire; 6MST, 6 min stepper test; 10STS, 10 times sit-to-stand test. 
Table 4 Correlations Between VSRQ and the Other Questionnaires at $T_{0}$ and $T_{2}$ and the Deltas $\left(T_{0-} T_{2}\right)$

\begin{tabular}{|l|l|l|l|}
\hline & & $\begin{array}{l}\text { MRF-28: } \\
\text { Global Score }\end{array}$ & $\begin{array}{l}\text { VQII: } \\
\text { Global Score }\end{array}$ \\
\hline T0 & $\begin{array}{l}\text { Correlation coefficient } \\
p \text { value }\end{array}$ & $\begin{array}{l}-0.685 \\
<0.000 \text { I }\end{array}$ & $\begin{array}{l}-0.691 \\
<0.000 \text { I }\end{array}$ \\
\hline T2 & Correlation coefficient & $\begin{array}{l}-0.686 \\
<0.000 I\end{array}$ & $\begin{array}{l}-0.753 \\
<0.000 I\end{array}$ \\
\hline \multirow{2}{*}{ Delta } & Correlation coefficient & $\begin{array}{l}-0.372 \\
<0.0001\end{array}$ & $\begin{array}{l}-0.423 \\
<0.000 I\end{array}$ \\
\hline
\end{tabular}

Abbreviations: MRF-28, Maugeri Foundation respiratory failure questionnaire; $T_{0}$, baseline (ie, before pulmonary rehabilitation); $T_{2}$, after pulmonary rehabilitation; VQII, COPD specific HRQoL questionnaire; VSRQ, visual simplified respiratory questionnaire.

Table 5 Determination of Minimal Clinically Important Difference Using Two Statistical Methods

\begin{tabular}{|l|l|l|l|}
\hline Method & $\begin{array}{l}\text { MRF-28: } \\
\text { Global } \\
\text { Score }\end{array}$ & $\begin{array}{l}\text { VQII: } \\
\text { Global } \\
\text { Score }\end{array}$ & $\begin{array}{l}\text { VSRQ: } \\
\text { Global } \\
\text { Score }\end{array}$ \\
\hline $\begin{array}{l}\text { Anchor based } \\
\text { ROC curve derived (Youden) }\end{array}$ & 28 & 5 & 5 \\
ROC curve derived & 24 & 1 & 2 \\
(“Minimax": minimizes the & & & \\
most frequent error) & & & \\
\hline Distribution based & & & \\
Half Standard deviation & 5.77 & 2.22 & 3.83 \\
Small Cohen's effect size (0.2) & 4.62 & 1.77 & 3.06 \\
MCID proposed & -5.2 & -2.0 & +3.4 \\
\hline
\end{tabular}

Abbreviations: MRF-28, Maugeri Foundation respiratory failure questionnaire; ROC, receiver operating characteristics; VQII, COPD specific HRQoL questionnaire; VSRQ, visual simplified respiratory questionnaire.

and), and social (eg, social relationship). Thus, an instrument dedicated to measure HRQoL needs to provide a global score, as well as evaluation of different subcomponents. Indeed, as indicated by Janssens et al, ${ }^{15}$ these subcomponents may be contributive to a finer analysis of the impact of PR on HRQoL in respiratory disease.

As noted by Smid et $\mathrm{al}^{38}$ the MCID is the smallest difference in a measurable clinical parameter perceived by the patient or clinician that indicates a meaningful change in the condition for better or worse. It can thus be used to assess the effect of therapies like home-based PR. MCID of -4 units has frequently been found for the $\mathrm{SGRQ}^{39}$ and even +3.4 for the VSRQ. ${ }^{3}$ Therefore, using anchor-based (with the VSRQ as anchor) and distribution-based methods, the MCID for MRF-28 and the VQ11 were calculated and identified as -5.2 units and -2.0 units, respectively. Consequently, as
MCID is patient derived scores that reflect changes in a clinical intervention that are meaningful for the patient, ${ }^{40}$ future studies in PR could also determine the number of responders (ie, patients with HRQoL score superior to MCID), rather than only raw data (ie, score of HRQoL).

\section{Limitations}

The cut-off points of MCID (ie, -5.2 and -2.0 units for MRF-28 and VQ11, respectively) were established from distribution-based methods rather than anchor-based methods because the area under the ROC curve was slightly less than 0.5 (0.481 for MRF-28 and 0.436 for VQ11), which raised the question of whether these two questionnaires are able to make sensitive distinctions between COPD patients who improved by at least -3.4 units on the VSRQ and those who did not. ${ }^{38}$ The current study therefore gives only an indicative value of the MCID of the MRF-28 and VQ11, rather than exact cut-off points. Moreover, $16.1 \%$ of patients did not complete the homebased PR. This result is close to that of previous studies (dropout ranged from 0 to 36\%) that proposed PR for COPD patients. ${ }^{41}$ These nonparticipants had worse baseline values (ie, older and greater airflow limitation) than those who completed PR. As Smid et $\mathrm{al}^{38}$ noted, this may well have affected the current results. Furthermore, the participants were all COPD patients and this should be considered when generalizing the results to other populations. Last, although significant correlations ( $p<0.0001)$ with moderate to high coefficients of correlation were found between the VSRQ and the other questionnaires (MRF-28 and VQ11) at $\mathrm{T}_{0}$ (ie, $\mathrm{r}=-0.685$ and -0.691 , respectively) and $\mathrm{T}_{2}$ (ie, $\mathrm{r}=-0.686$ and -0.753 , respectively), lower significant coefficients of correlation between deltas were noted (ie, $\mathrm{r}=-0.372$ and -0.423 , respectively, $p<0.0001$, Table 5). Despite the findings of similar coefficients of correlation, ${ }^{38}$ moderate correlation coefficients $(r \geq 0.5)$ are ideally needed to prevent a wide range in MCID. ${ }^{42}$ These observations therefore suggest that the MCID of our study are indicative values and specifically adapted for PR in COPD patients.

\section{Conclusion}

This study shows that home-based PR is an efficient nonpharmacological therapy that improves exercise tolerance, HAD, and HRQoL in COPD patients. Moreover, the results confirm (from VSRQ) the convergent validity of the MRF-28 and VQ11. Therefore, both questionnaires have good measurement properties and are useful tools to measure COPD- 
specific HRQoL in routine practice. Last, we suggest MCID of -5.2 units and -2.0 units for the MRF-28 and VQ11, respectively, to assess the effect of $\mathrm{PR}$ in COPD patients.

\section{Acknowledgements}

The authors would like to thank the rehabilitation team who managed the patients: S. Duriez, M. Grosbois, M. Lambinet, G. Tywoniuk, F. Urbain, and V. Wauquier. The authors also express their thanks to the 'Institut de Recherche Interdisciplinaire Homme Société (Université de RouenNormandie)' for their contribution in this study.

\section{Disclosure}

JMG received financial support from Adair, Aeris Santé, Bastide, France Oxygène, Homeperf, LVL, Medopale, NorOx, Orkyn, Santélys, SOS Oxygène, Sysmed, VitalAire, and ARS Hauts-de-France for the home-based PR program. The remaining authors report no conflicts of interest in this work.

\section{References}

1. Barreiro E, Gea J. Respiratory and limb muscle dysfunction in COPD. COPD. 2015;12(4):413-426. doi:10.3109/15412555.2014.974737

2. Spruit MA, Singh SJ, Garvey C, et al. An official American Thoracic Society/European Respiratory Society statement: key concepts and advances in pulmonary rehabilitation. Am J Respir Crit Care Med. 2013;188(8):13-64. doi:10.1164/rccm.201309-1634ST

3. Perez T, Arnould B, Grosbois JM, et al. Validity, reliability, and responsiveness of a new short Visual Simplified Respiratory Questionnaire (VSRQ) for health-related quality of life assessment in chronic obstructive pulmonary disease. Int $J$ Chron Obstruct Pulmon Dis. 2009;4:9-18.

4. Mc Carthy B, Casey D, Devane D, Murphy K, Murphy E, Lacasse Y. Pulmonary rehabilitation for chronic obstructive pulmonary disease. Cochrane Database Syst Rev. 2015;2:1-209.

5. Coquart JB, Le Rouzic O, Racil G, Wallaert B, Grosbois JM. Reallife feasibility and effectiveness of home-based pulmonary rehabilitation in chronic obstructive pulmonary disease requiring medical equipment. Int J Chron Obstruct Pulmon Dis. 2017;12:3549-3556. doi:10.2147/COPD.S150827

6. Liu XL, Tan JY, Wang T, et al. Effectiveness of home-based pulmonary rehabilitation for patients with chronic obstructive pulmonary disease: a meta-analysis of randomized controlled trials. Rehabil Nurs. 2014;39(1):36-59. doi:10.1002/rnj.112ISTEX

7. Wuytack F, Devane D, Stovold E, et al. Comparison of outpatient and home-based exercise training programmes for COPD: a systematic review and meta-analysis. Respir. 2018;23(3):272-283. doi:10.1111/resp.13224

8. Lareau SC, Breslin EH, Meek PM. Functional status instruments: outcome measure in the evaluation of patients with chronic obstructive pulmonary disease. Heart Lung. 1996;25(3):212-224. doi:10.1016/S0147-9563(96)80032-X

9. Glaab T, Vogelmeier C, Buhl R. Outcome measures in chronic obstructive pulmonary disease (COPD): strengths and limitations. Respir Res. 2010;11:79. doi:10.1186/1465-9921-11-79

10. Jones AM. St George's Respiratory Questionnaire: Manual. London, GB: University of London; 2009.
11. Guyatt GH, Berman LB, Townsend M, Pugsley SO, Chambers LW. A measure of quality of life for clinical trials in chronic lung disease. Thorax. 1987;42(10):773-778. doi:10.1136/thx.42.10.773ISTEX

12. Schunemann HJ, Puhan M, Goldstein R, Jaeschke R, Guyatt GH. Measurement properties and interpretability of the Chronic respiratory disease questionnaire (CRQ). COPD. 2005;2(1):81-89. doi:10.1081/ COPD-200050651

13. Ninot G, Soyez F, Fiocco S, Nassih K, Morin AJS, Prefaut C. Le VQ11, un questionnaire de qualité de vie spécifique à la BPCO utilisable en clinique. Rev Mal Respir. 2010;27(5):472-481. doi:10.1016/j.rmr.2010.03.020

14. Tillie-Leblond I, Masure F. "EXACO": four year follow-up of exacerbations in a cohort of patients with COPD. Rev Mal Respir. 2006;23(4):377-384. doi:10.1016/S0761-8425(06)71607-2

15. Janssens JP, Heritier-Praz A, Carone M, et al. Validity and reliability of a French version of the MRF-28 health-related quality of life questionnaire. Respiration. 2004;71(6):567-574. doi:10.1159/000081756

16. Coquart JB, Grosbois J-M, Olivier C, Bart F, Castres I, Wallaert B. Home-based neuromuscular electrical stimulation improves exercise tolerance and health-related quality of life in patients with chronic obstructive pulmonary disease. Int J Chron Obstruct Pulmon Dis. 2016;11:1189-1197. doi:10.2147/COPD.S105049

17. Vivodtzev I, Pepin JL, Vottero G, et al. Improvement in quadriceps strength and dyspnea in daily tasks after 1 month of electrical stimulation in severely deconditioned and malnourished COPD. Chest. 2006;129(6):1540-1548. doi:10.1378/chest.129.6.1540

18. Carone M, Patessio A, Ambrosino N, et al. Efficacy of pulmonary rehabilitation in chronic respiratory failure (CRF) due to chronic obstructive pulmonary disease (COPD): the Maugeri study. Respir Med. 2007;101(12):2447-2453. doi:10.1016/j.rmed.2007.07.016

19. Grosbois J-M, Gicquello A, Langlois C, et al. Long term evaluation of home-based pulmonary rehabilitation in patients with chronic obstructive pulmonary disease. Int J Chron Obstruct Pulmon Dis. 2015;25(10):2037-2044.

20. Vitacca M, Kaymaz D, Lanini B, et al. Non-invasive ventilation during cycle exercise training in patients with chronic respiratory failure on long-term ventilatory support: a randomized controlled trial. Respir. 2018;23(2):182-189. doi:10.1111/resp.13181

21. Ninot G, Soyez F, Prefaut C. A short questionnaire for the assessment of quality of life in patients with chronic obstructive pulmonary disease: psychometric properties of VQ11. Health Qual Life Outcomes. 2013;11:179. doi:10.1186/1477-7525-11-179

22. Von Elm E, Altman DG, Egger M, Pocock SJ, Gotzsche PC, Vandenbroucke JP. The Strengthening the Reporting of Observational Studies in Epidemiology (STROBE) statement: guidelines for reporting observational studies. Int J Surg. 2014;12 (12):1495-1499. doi:10.1016/j.ijsu.2014.07.013

23. Olivier C, Grosbois JM, Cortot AB, et al. Real-life feasibility of home-based pulmonary rehabilitation in chemotherapy-treated patients with thoracic cancers: a pilot study. BMC Cancer. 2018;18 (1):178. doi:10.1186/s12885-018-4102-6

24. Vogelmeier CF, Criner GJ, Martinez FJ, et al. Global strategy for the diagnosis, management, and prevention of chronic obstructive lung disease 2017 report. GOLD executive summary. Am J Respir Crit Care Med. 2017;195(5):557-582. doi:10.1164/rccm.201701-0218PP

25. Netz Y, Ayalon M, Dunsky A, Alexander N. 'The multiple-sit-tostand' field test for older adults: what does it measure? Gerontology. 2004;50(3):121-126. doi:10.1159/000076769

26. Mesquita R, Wilke S, Smid DE, et al. Measurement properties of the timed up \& go test in patients with COPD. Chronic Respir Dis. 2016;13(4):344-352. doi:10.1177/1479972316647178

27. Grosbois J-M, Riquier C, Chehere B, et al. Six-minute stepper test: a valid clinical exercise tolerance test for COPD patients. Int J Chron Obstruct Pulmon Dis. 2016;11:657-663. doi:10.2147/ COPD.S98635 
28. Zigmond AS, Snaith RP. The hospital anxiety and depression scale. Acta Psychiatr Scand. 1983;67(6):361-370. doi:10.1111/acp.1983.67. issue-6

29. Munro BH. Statistical Methods for Health Care Research. 3th ed. Philadelphia: Lippincott; 1997.

30. Revicki D, Hays RD, Cella D, Sloan J. Recommended methods for determining responsiveness and minimally important differences for patient-reported outcomes. J Clin Epidemiol. 2008;61(2):102-109. doi:10.1016/j.jclinepi.2007.03.012

31. Cohen J. Statistical Power Analysis for the Behavioral Sciences. 2nd ed. Hillsdale, NJ: Erlbaum; 1988.

32. Copay AG, Subach BR, Glassman SD, Polly DW, Schuler TC. Understanding the minimum clinically important difference: a review of concepts and methods. Spine J. 2007;7(5):541-546. doi:10.1016/j.spinee.2007.01.008

33. Schembri S, Anderson W, Morant S, et al. A predictive model of hospitalisation and death from chronic obstructive pulmonary disease. Respir Med. 2009;103(10):1461-1467. doi:10.1016/j.rmed.2009.04.021

34. Schonmann M, Sievi NA, Clarenbach CF, et al. Physical activity and the frequency of acute exacerbations in patients with chronic obstructive pulmonary disease. Lung. 2015;193(1):63-70. doi:10.1007/ s00408-014-9673-7

35. Grosbois JM, Le Rouzic O, Monge E, Bart F, Wallaert B. La réhabilitation respiratoire: évaluation de deux types de prise en charge, ambulatoire versus domicile. Rev Pneumol Clin. 2013;69 (1):10-17. doi:10.1016/j.pneumo.2012.11.003
36. Tonnel AB, Perez T, Grosbois JM, Verkindre C, Bravo ML, Brun M. Effect of tiotropium on health-related quality of life as a primary efficacy endpoint in COPD. Int J Chron Obstruct Pulmon Dis. 2008;3 (2):301-310. doi:10.2147/COPD.S2463

37. Mahler DA. How should health-related quality of life be assessed in patients with COPD? Chest. 2000;117(2):54-57. doi:10.1378/ chest.117.2 suppl.54S

38. Smid DE, Franssen FM, Houben-Wilke S, et al. Responsiveness and MCID estimates for CAT, CCQ, and HADS in patients with COPD undergoing pulmonary rehabilitation: a prospective analysis. $\mathrm{J} \mathrm{Am}$ Med Dir Assoc. 2017;18(1):53-58. doi:10.1016/j.jamda.2016.08.002

39. Jones PW. St. George's respiratory questionnaire: MCID. Copd. 2005;2(1):75-79. doi:10.1081/COPD-200050513

40. Cook CE. Clinimetrics corner: the minimal clinically important change score (MCID): a necessary pretense. JMMT. 2008;16 (4):82-83. doi:10.1179/jmt.2008.16.4.82E

41. Bjoernshave B, Korsgaard J, Nielsen CV. Does pulmonary rehabilitation work in clinical practice? A review on selection and dropout in randomized controlled trials on pulmonary rehabilitation. Clin Epidemiol. 2010;2:73-83. doi:10.2147/CLEP.S9483

42. Schunemann HJ, Griffith L, Jaeschke R, Goldstein R, Stubbing D, Guyatt GH. Evaluation of the minimal important difference for the feeling thermometer and the St. George's respiratory questionnaire in patients with chronic airflow obstruction. J Clin Epidemiol. 2003;56 (12):1170-1176. doi:10.1016/S0895-4356(03)00115-X

\section{Publish your work in this journal}

The International Journal of COPD is an international, peer-reviewed journal of therapeutics and pharmacology focusing on concise rapid reporting of clinical studies and reviews in COPD. Special focus is given to the pathophysiological processes underlying the disease, intervention programs, patient focused education, and self management protocols. This journal is indexed on PubMed Central, MedLine and CAS. The manuscript management system is completely online and includes a very quick and fair peer-review system, which is all easy to use. Visit http://www.dovepress.com/testimonials.php to read real quotes from published authors. 